\title{
PERANCANGAN DAN ANALISIS ENTERPRISE ARCHITECTURE YAYASAN KESEHATAN (YAKES) TELKOM PADA DOMAIN ARSITEKTUR TEKNOLOGI DENGAN MENGGUNAKAN FRAMEWORK TOGAF ADM
}

\author{
${ }^{1}$ Irma Angraeini, ${ }^{2}$ Mochamad Teguh Kurniawan, ${ }^{3}$ Rahmat Mulyana \\ 1, 2, ${ }^{3}$ Program Studi Sistem Informasi, Fakultas Rekayasa Industri, Telkom University \\ 1irmaangraeini@students.telkomuniversity.ac.id, ${ }^{2}$ teguhkurniawan@telkomuniversity.ac.id, \\ ${ }^{3}$ rahmatmoelyana@telkomuniversity.ac.id
}

\begin{abstract}
Abstrak-Yayasan Kesehatan Telkom merupakan perusahaan yang bergerak dalam bidang kesehatan. Untuk melaksanakan aktivitas bisnisnya dalam mencapai tujuan perusahaan, Yayasan Kesehatan Telkom membutuhkan sistem informasi yang didukung oleh infrastruktur teknologi yang memadai. Selain itu, dengan adanya kebijakan pemerintah terkait Badan Penyelenggara Jaminan Sosial (BPJS) menjadi salah satu tantangan dalam dunia kesehatan untuk menyelaraskan strategi bisnis dan strategi teknologi informasi sesuai dengan kebutuhan dari BPJS. Enterprise architecture merupakan salah satu metode yang dapat digunakan untuk menyelarasakan strategi bisnis dan strategi teknologi informasi yang dirancang sesuai dengan kebutuhan bisnis. TOGAF ADM dapat menjadi salah satu framework yang dapat dijadikan pedoman dalam pembuatan enterprise architecture. Penelitian ini menghasilkan blueprint arsitektur teknologi yang digunakan sebagai acuan perancangan dan pengembangan teknologi Yayasan Kesehatan Telkom terkait kerjasamanya dengan BPJS. Harapannya dengan adanya perancangan arsitektur teknologi, teknologi yang ada pada Yayasan Kesehatan Telkom saat ini dapat berkembang ke arah yang lebih baik sesuai dengan perkembangan bisnis dan kerjasama yang dilakukan dengan BPJS dapat berjalan dengan lancar tanpa ada kendala yang berarti.
\end{abstract}

Keyword: Enterprise architecture, blueprint, arsitektur teknologi, TOGAF ADM, Yayasan Kesehatan Telkom, BPJS.

\section{PENDAHULUAN}

Pada tahun 2011 pemerintah Indonesia mengeluarkan sebuah kebijakan baru dalam dunia kesehatan mengenai Sistem Jaminan Sosial Nasional (SJSN) yang terkait dengan Badan Penyelenggara Jaminan Sosial (BPJS) [1]. Kebijakan tersebut memberikan dampak kepada perusahaan di seluruh Indonesia, khususnya dalam hal pelayanan kesehatan. Saat ini, beberapa perusahaan yang bergerak di bidang layanan kesehatan sedang melakukan persiapan untuk mematuhi regulasi pemerintah tersebut [2].

Dengan adanya kerjasama dengan BPJS, maka akan terdapat beberapa perubahan pada layanan kesehatan yang ada saat ini guna menyesuaikan dengan kebijakan-kebijakan yang ditetapkan oleh BPJS. Perubahan yang terjadi mencakup perubahan dari sisi bisnis dan infrastruktur yaitu sistem informasi dan teknologi. Salah satu perusahaan yang bergerak di bidang layanan kesehatan yang sedang mempersiapkan diri adalah Yayasan Kesehatan Telkom.

Pada awalnya, Yayasan Kesehatan Telkom dibangun hanya untuk melayani kesehatan pegawai Telkom dan keluarganya, serta pensiunan Telkom dan keluarganya. Namun dengan adanya kebijakan terkait BPJS, klinik-klinik yang dimiliki oleh Yayasan Kesehatan Telkom diharuskan untuk melayani peserta BPJS selain karyawan dan pensiunan PT. Telkom beserta keluarganya. Sehingga, diperlukan suatu strategi agar perubahan tersebut dapat dilakukan dan tidak menimbulkan permasalahan yang besar kedepannya. Diawali dengan adanya perbedaan sistem informasi yang dimiliki, tentu akan mempengaruhi infrastruktur teknologi yang dapat membantu mengintegrasikan sistem informasi yang ada. Dengan melihat tantangan yang dialami, dibutuhkan enterprise architecture untuk mendukung keselarasan berlangsungnya strategi bisnis dengan strategi teknologi informasi pada Yayasan Kesehatan Telkom. Dalam melakukan perancangan enterprise architecture dibutuhkan suatu framework yang akan digunakan sebagai acuan. TOGAF ADM merupakan framework yang akan digunakan sebagai acuan dalam merancang enterprise architecture karena TOGAF ADM melibatkan stakeholder dalam melakukan pengambilan keputusannya, menggunakan acuan best practice, serta adanya requirement management yang tidak dimiliki oleh framework lainnya. Requirement management sangat berguna untuk menentukan requirement dari suatu enterprise karena merupakan input dari setiap fase pada TOGAF ADM dalam menentukan arsitektur target [3]. Penelitian ini bertujuan untuk menghasilkan blueprint perancangan dan analisis kebutuhan dari sisi infrastruktur teknologi berupa katalog, diagram, dan matriks yang nantinya dibutuhkan oleh Yayasan Kesehatan Telkom dalam mengembangkan bisnisnya ketika bekerja sama dengan BPJS. 


\section{METODE PENELITIAN}

Model konseptual merupakan Gambaran yang dibuat berdasarkan teori dan hipotesis yang berkaitan dengan penelitian yang sedang dilakukan. Model ini digunakan sebagai kerangka berpikir yang menjelaskan konsep secara terstruktur dari penelitian untuk menghasilkan output yang sesuai dengan tujuan penelitian. Gambar 1 adalah model konseptual dalam melakukan perancangan dan analisis terhadap Yayasan Kesehatan Telkom.

Model konseptual memiliki tiga elemen utama yaitu input, process, dan output. Dari diagram konseptual tersebut, dalam merancang arsitektur teknologi dibutuhkan input yaitu dokumen visi dan misi perusahaan, dokumen rencana jangka panjang, dokumen kondisi bisnis dan TI saat ini, fase preliminary, dan fase architecture vision. Dari beberapa input tersebut akan masuk ke dalam proses perancangan arsitektur dimana dimulai dari arsitektur bisnis yang menghasilkan organizational unit, business service, dan operation location, kemudian perancangan arsitektur sistem informasi, dan dilanjutkan dengan perancangan arsitektur teknologi yaitu melakukan identifikasi komponen teknologi fisik dan logik, serta platform service teknologi yang akan digunakan untuk membuat beberapa artifak seperti environment and location diagram, platform decomposition diagram, dan communication engineering diagram yang sesuai dengan TOGAF ADM. Dari proses perancangan arsitektur teknologi, akan dihasilkan sebuah keluaran berupa blueprint dari masing-masing arsitektur.

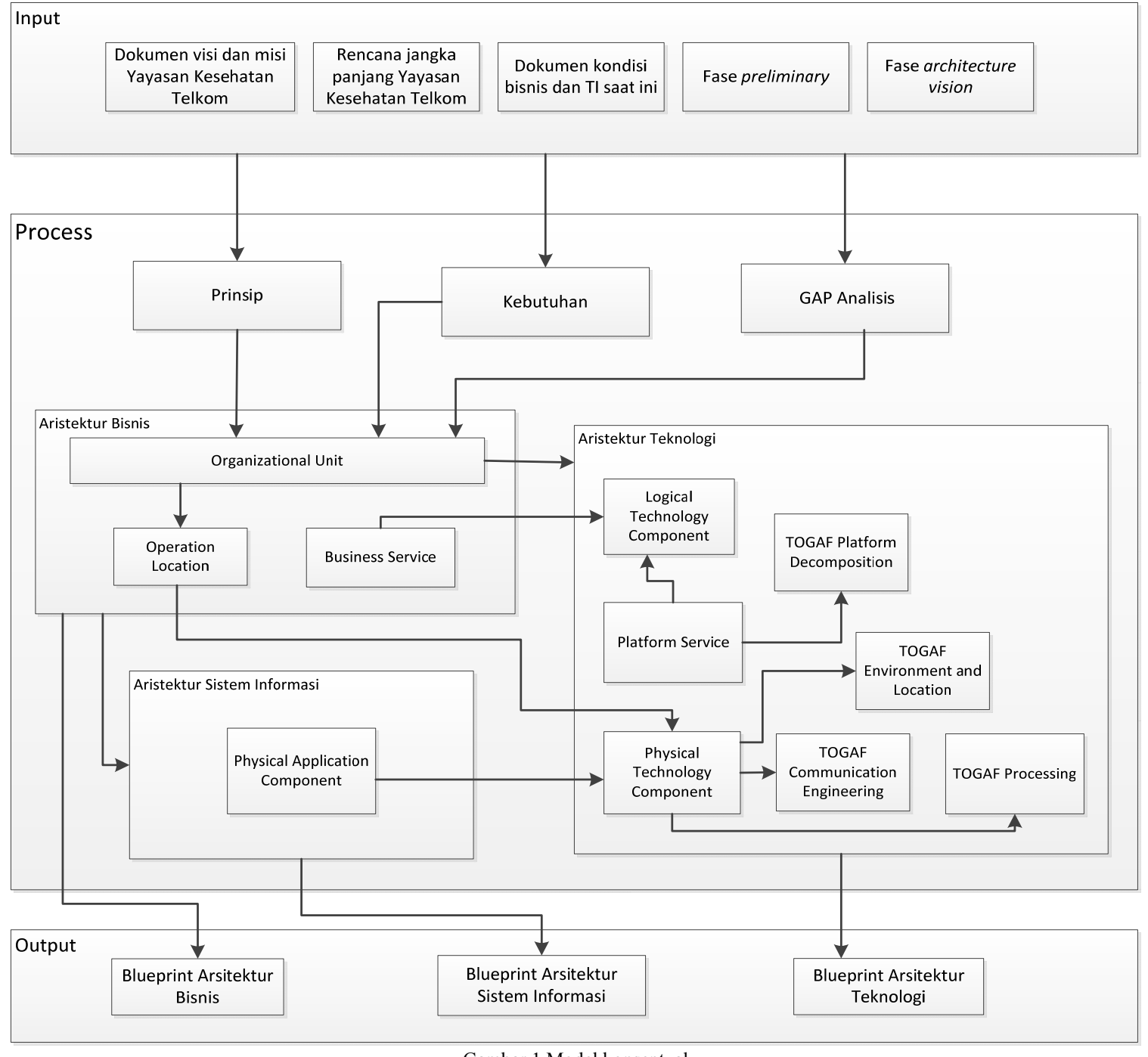

Gambar 1 Model konseptual

Perancangan dan Analisis Enterprise Architecture Yayasan Kesehatan (Yakes) Telkom pada Domain Arsitektur Teknologi dengan Menggunakan Framework TOGAF ADM Irma Angraeini, Mochamad Teguh Kurniawan, Rahmat Mulyana (hal. 1 - 8) 


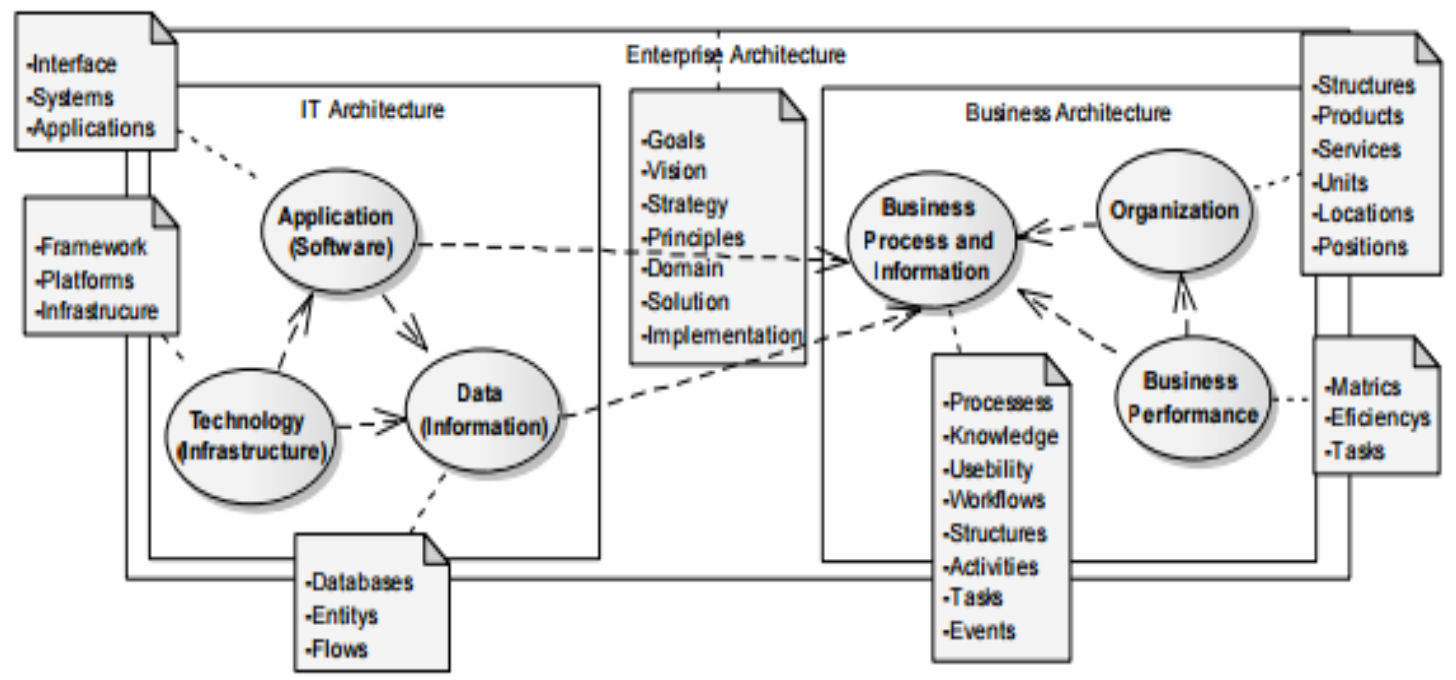

Gambar 2 Model prinsip enterprise architecture [4]

\section{HASIL DAN PEMBAHASAN}

\section{III.1 Model Prinsip Enterprise Architecture}

Model prinsip enterprise architecture mengGambarkan keterkaitan antara komponen-komponen arsitektur IT dengan arsitektur bisnis. Arsitektur IT terdiri dari 3 buah komponen yaitu application (software), technology (infrastructure), dan data (information). Sedangkan arsitektur bisnis juga terdiri dari 3 buah komponen yaitu business process and information, organization, dan business performance. Gambar 2 adalah model prinsip enterprise architecture baik dari sisi IT, bisnis, dan keseluruhan enterprise architecture:

\section{III.2 Arsitektur Teknologi}

Arsitektur teknologi merupakan arsitektur yang mendukung aplikasi-aplikasi yang sedang ataupun yang akan diterapkan agar dapat berjalan dengan baik. Identifikasi yang dilakukan meliputi sistem operasi, manajemen data, aplikasi, perangkat keras, komunikasi, komputasi pemakai, dan keamanan. Hasil dari identifikasi tersebut dituangkan ke dalam artifak-artifak yang ada pada TOGAF ADM (Tabel I).

Untuk mengetahui kebutuhan dari arsitektur teknologi, dibutuhkan analisis value chain yang menjelaskan aktivitas utama dan aktivitas pendukung yang ada di perusahaan serta tujuan utama dari perusahaan tersebut. Dengan mengetahui aktivitas yang berjalan pada perusahaan, maka akan memudahkan dalam melakukan analisis kebutuhan yang sesuai dengan aktivitas yang sedang berjalan. Gambar 3 merupakan value chain dari Yayasan Kesehatan Telkom.

Dapat dilihat pada Gambar 3 bahwa terdapat beberapa aktivitas utama dari Yayasan Kesehatan Telkom yang terdiri dari inbound, operasional, outbond, marketing and sales, dan service. Aktivitas yang termasuk inbound adalah kepesertaan yang terdiri dari pengelolaan kepesertaan dan pengelolaan kartu peserta. Aktivitas operasional pada Yayasan Kesehatan Telkom meliputi pelayanan dan pengendalian kesehatan. Kemudian aktivitas pada outbond merupakan hasil dari aktivitas inbound yaitu pengelolaan medical record dan pelaporan kepesertaan pegawai dan pension. Pada marketing and sales aktivitas yang dilakukan adalah melakukan investasi yang dimulai dari perencanaan hingga pengendalian dan pelaporan. Aktivitas utama yang terakhir adalah service yaitu dengan melakukan pengadaan dan aset. Untuk mendukung berjalannya seluruh aktivitas utama pada Yayasan Kesehatan Telkom, maka dilakukan beberapa aktivitas pendukungnya seperti dari sisi SDM (administrasi pegawai, kinerja dan kompetensi), keuangan (mengelola anggaran, pajak, dan perbendaharaan), sistem informasi yang dimiliki dan sedang berjalan, serta secretariat dan legal (kesekretariatan dan legal). Keseluruhan aktivitas tersebut dilakukan untuk mencapai satu tujuan yaitu customer satisfaction atau kepuasan pelanggan.

TABEL I

ARTIFAK ARSITEKTUR TEKNOLOGI (The Open Group, 2011)

\begin{tabular}{|c|c|}
\hline Domain Arsitektur & Artifak \\
\hline $\begin{array}{l}\text { Technology } \\
\text { Architecture }\end{array}$ & $\begin{array}{l}\text { 1. Technology standard } \\
\text { catalog } \\
\text { 2. Technology portfolio } \\
\text { catalog } \\
\text { 3. System/technology } \\
\text { matrix } \\
\text { 4. Environment and } \\
\text { location diagram } \\
\text { 5. Platform decomposition } \\
\text { diagram } \\
\text { 6. Processing diagram } \\
\text { 7. Communications } \\
\text { engineering diagram }\end{array}$ \\
\hline
\end{tabular}




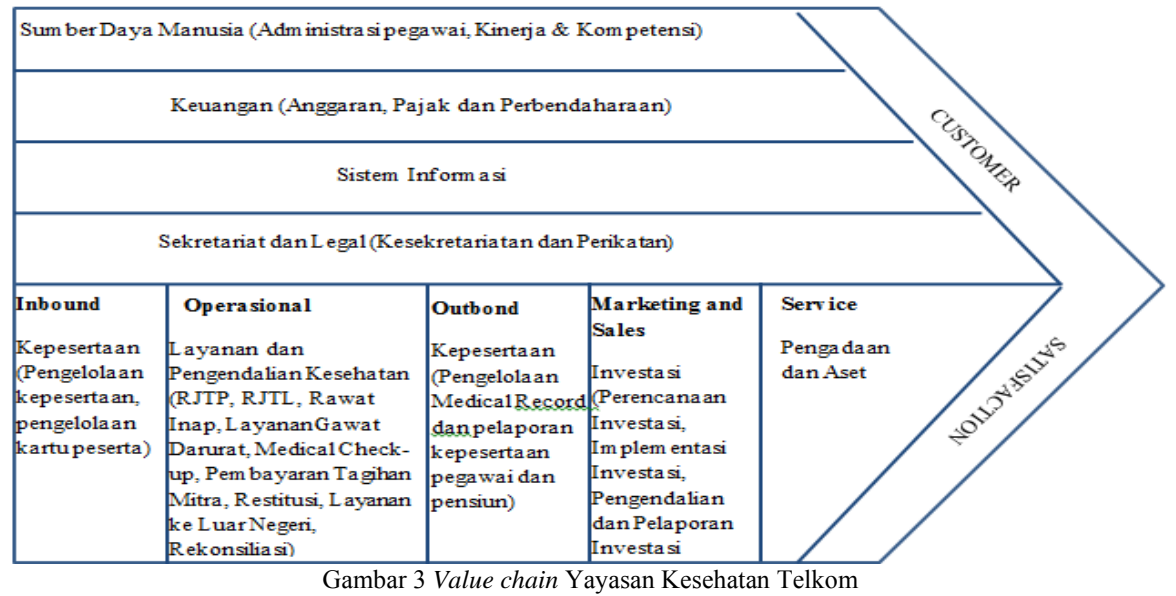

Berdasarkan analisis value chain di atas, akan didapatkan kebutuhan bisnis dan kebutuhan sistem informasi yang menyebabkan munculnya kebutuhan teknologi informasi sebagai pendukung. Berikut adalah identifikasi arsitektur teknologi pada Yayasan Kesehatan Telkom:

a. Topologi WAN

Topologi WAN menjelaskan Gambaran jaringan dari keseluruhan perusahaan mulai dari kantor pusat sampai keterhubungannya dengan Divre di seluruh Indonesia. Topologi jaringan WAN pada Gambar 4 untuk Yayasan Kesehatan Telkom menunjukkan bahwa terdapat penambahan beberapa keamanan jaringan dan adanya penambahan integrasi dengan WAN milik BPJS. Selain itu, juga terdapat redundansi link dari cloud masingmasing provider (VPN IP dan Astinet) ke router utama, dari router utama ke router-router di setiap Divre, serta adanya link untuk menghubungkan antar router pada setiap Divre.

b. Topologi LAN

Topologi LAN yang digunakan pada penelitian ini adalah LAN yang berada pada kantor pusat Yayasan Kesehatan Telkom. Topologi ini menjelaskan bagaimana Gambaran jaringan lokal yang ada. Topologi jaringan LAN pada Gambar 5 untuk Yayasan Kesehatan Telkom, menunjukkan bahwa terdapat penambahan satu buah DNS server dan keamanan jaringan yang sekiranya dibutuhkan. Kemudian terdapat redundansi link yaitu dari cloud masingmasing provider (VPN IP dan Astinet) ke router kantor pusat, dari router ke dua buah switch utama, kemudian dari masing-masing switch utama ke setiap server, dan dari switch utama ke switch pada masing-masing cabang. Selain itu, juga terdapat penambahan cloud milik BPJS dimana nantinya akan digunakan apabila kerjasama diantara keduanya telah berjalan.

\section{A. Fase preliminary}

Fase preliminary menjelaskan mengenai persiapan dan inisiasi aktivitas-aktivitas yang harus dipersiapkan untuk memenuhi tujuan bisnis pada arsitektur enterprise yang baru. Pada fase ini terdapat beberapa langkah kerja seperti menentukan ruang lingkup organisasi, mendefinisikan dan membangun tim dari enterprise architecture, mengidentifikasi dan menetapkan prinsip arsitektur, serta memilih dan menyesuaikan framework arsitektur [6]. Berikut adalah prinsip dari arsitektur teknologi:

TABEL II

PRINSIP ARSITEKTUR TEKNOLOGI [6]

\begin{tabular}{|l|ll|}
\hline Domain Arsitektur & \multicolumn{2}{|c|}{ Nama Prinsip Arsitektur } \\
\hline Technology & 1. & Control technical \\
architecture & & diversity \\
& 2. & Interoperability \\
& 3. & Responsive change \\
& & management \\
& 4. & Requirement based \\
& & change \\
& 5. Confidentiality \\
& 6. Integrity \\
& 7. Availability \\
\hline
\end{tabular}

B. Fase architecture vision

Fase architecture vision merupakan fase awal dari TOGAF ADM. Termasuk didalamnya informasi mengenai pendefinisian ruang lingkup, pengidentifikasian stakeholder, pembuatan architecture vision, serta meminta dan memperoleh persetujuan [6].

\section{Fase arsitektur teknologi}

Langkah awal dalam perancangan arsitektur teknologi adalah melakukan identifikasi requirement. Berikut adalah hasil identifikasi requirement Yayasan Kesehatan Telkom: 


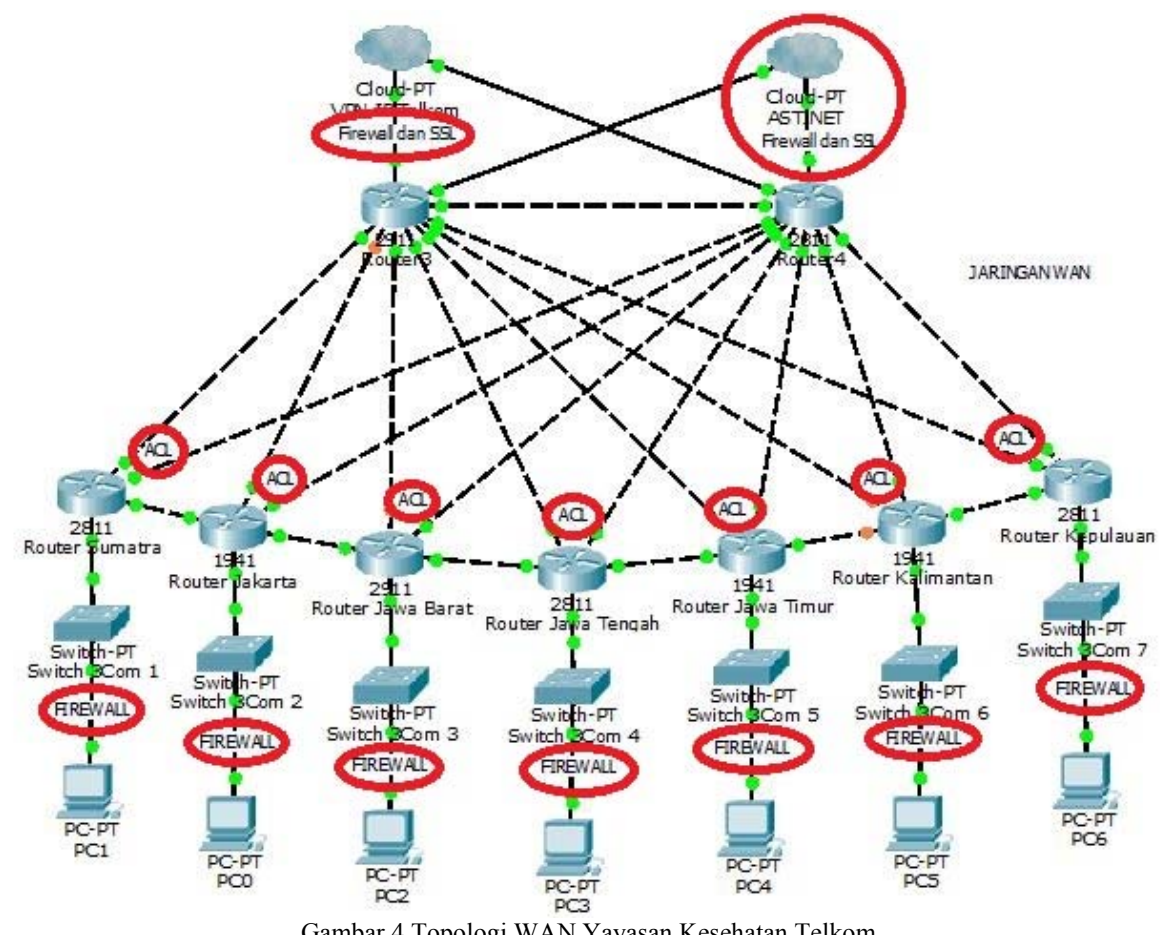

Gambar 4 Topologi WAN Yayasan Kesehatan Telkom

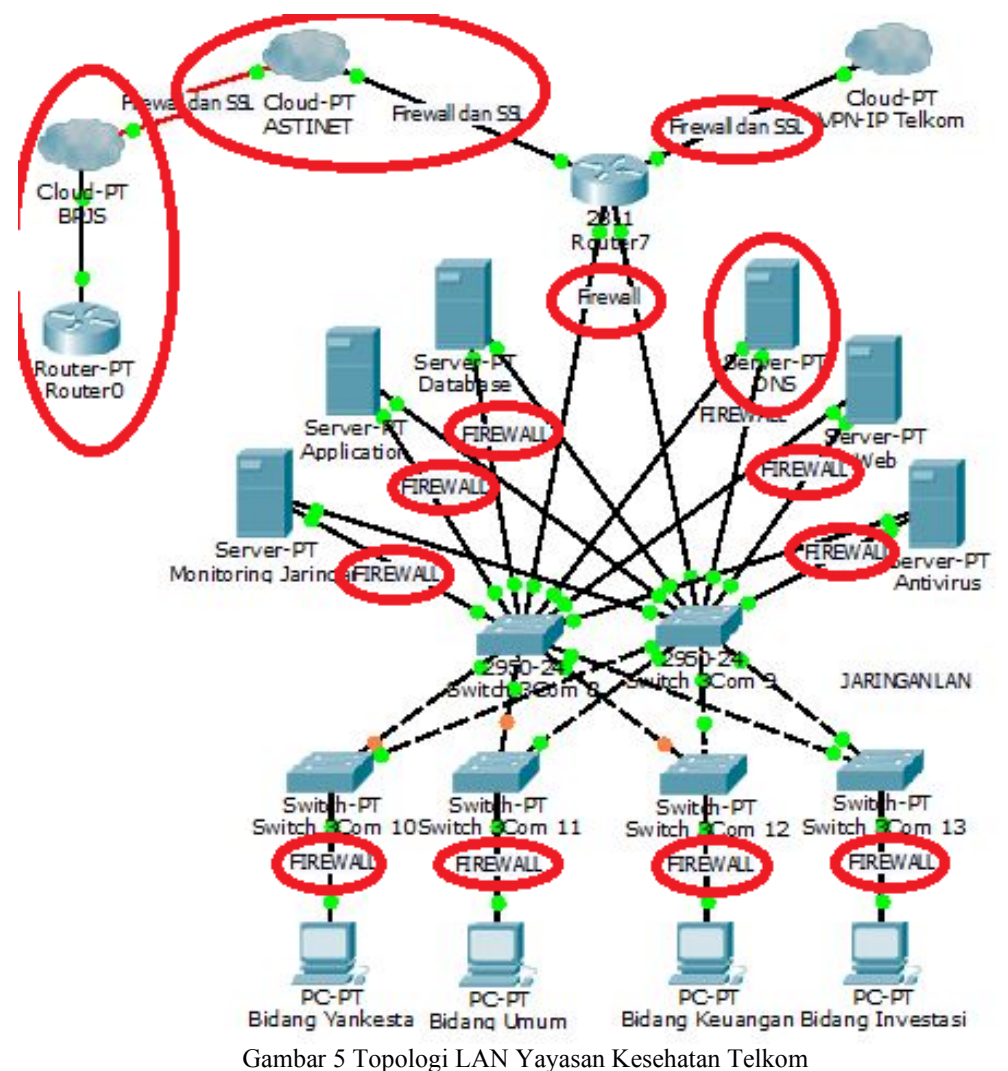

Jurnal Rekayasa Sistem \& Industri

Volume 2, Nomor 4, Oktober 2015 
TABEL III

REQUIREMENT ARSITEKTUR TEKNOLOGI

\begin{tabular}{|c|l|}
\hline No & \multicolumn{1}{|c|}{ Requirement } \\
\hline 1 & $\begin{array}{l}\text { Kemampuan untuk menghubungkan aplikasi } \\
\text { meliputi platform yang berbeda-beda dengan } \\
\text { berbasis web services }\end{array}$ \\
\hline 2 & $\begin{array}{l}\text { Kemampuan integrasi server dengan backup secara } \\
\text { realtime }\end{array}$ \\
\hline 3 & $\begin{array}{l}\text { Penggunaan teknologi yang sudah sesuai dengan } \\
\text { kebutuhan }\end{array}$ \\
\hline 4 & $\begin{array}{l}\text { Kemampuan untuk memastikan layanan } \\
\text { pertukaran informasi yang aman sesuai dengan } \\
\text { kebutuhan dari aplikasi yang telah dikembangkan }\end{array}$ \\
\hline 5 & $\begin{array}{l}\text { Kemampuan memanfaatkan DNS untuk } \\
\text { mengakses setiap aplikasi }\end{array}$ \\
\hline 6 & $\begin{array}{l}\text { Adanya redundansi yang berfungsi sebagai jalur } \\
\text { backup atau jalur alternatif }\end{array}$ \\
\hline 7 & $\begin{array}{l}\text { Mampu menyesuaikan hak akses yang tepat untuk } \\
\text { management bandwidth }\end{array}$ \\
\hline 8 & Adanya monitoring sistem dan infrastruktur \\
\hline 9 & $\begin{array}{l}\text { Koneksi jaringan telah terhubung dengan semua } \\
\text { perangkat teknologi }\end{array}$ \\
\hline 10 & $\begin{array}{l}\text { Sudah terdapat pencatatan daftar aset infrastruktur } \\
\text { untuk mempermudah maintenance }\end{array}$ \\
\hline 11 & $\begin{array}{l}\text { Terdapat pencatatan akses untuk pengunjung data } \\
\text { center }\end{array}$ \\
\hline 12 & $\begin{array}{l}\text { Adanya pengawasan instalasi software dan } \\
\text { hardware }\end{array}$ \\
\hline 13 & $\begin{array}{l}\text { Sudah menetapkan jadwal maintenance secara } \\
\text { rutin }\end{array}$ \\
\hline 14 & $\begin{array}{l}\text { Aplikasi pada perusahaan berbasis web sehingga } \\
\text { mudah untuk melakukan integrasi data secara } \\
\text { realtime dan efisiensi kerja }\end{array}$ \\
\hline &
\end{tabular}

Selain melakukan identifikasi requirement, terdapat juga beberapa blueprint berupa diagram berdasarkan TOGAF ADM yang diGambarkan dengan tujuan memberikan Gambaran mengenai perancangan dan analisis arsitektur teknologi yang telah dibuat. Berikut adalah diagram-diagram yang diGambarkan pada penelitian ini:

a. Environmenst and locations diagram

Diagram ini mengGambarkan identifikasi teknologi dan atau aplikasi apa yang digunakan dan dimana teknologi dan atau aplikasi tersebut diimplementasikan (The Open Group, 2011). Yayasan Kesehatan Telkom memiliki 4 lokasi untuk menjalankan bisnisnya yaitu kantor pusat Yayasan Kesehatan Telkom yang terbagi menjadi 4 bidang yaitu bidang umum, bidang Yankesta, bidang keuangan, dan bidang investasi, TPKK yang merupakan klinik yang dimiliki oleh Yayasan Kesehatan Telkom, TPKU yang merupakan mitra, dan Divre yang terdiri dari 7 area di Indonesia. Pada diagram ini terdapat penambahan lokasi yaitu BPJS serta penambahan aplikasi P-Care milik BPJS pada bidang Yankesta, TPKK, dan Divre.

b. Platform decomposition diagram

Diagram ini mengGambarkan platform teknologi yang mendukung operasional arsitektur sistem informasi yaitu aplikasi fisiknya. Diagram ini mencakup semua aspek dari platform infrastruktur dan memberikan Gambaran tentang platform teknologi milik perusahaan (The Open Group, 2011). Pada Gambar 5 menunjukkan pengGambaran integrasi aplikasi dengan masingmasing platform teknologi yang digunakan. Seperti aplikasi Medrec dan e-apotek yang diintegrasikan menggunakan platform web service, kemudian integrasi aplikasi Medrec dengan DOT dan e-apotek dengan DOT yang menggunakan platform trigger. Adanya kerjasama dengan BPJS menyebabkan penambahanan satu buah aplikasi yaitu P-Care milik BPJS yang terintegrasi dengan aplikasi Medrec dan Sika. Selain itu, terdapat sebuah platform teknologi yaitu bridging system dengan berbasis web service dimana platform tersebut yang digunakan untuk menghubungkan aplikasi P-Care dengan aplikasi Medrec dan Sika.

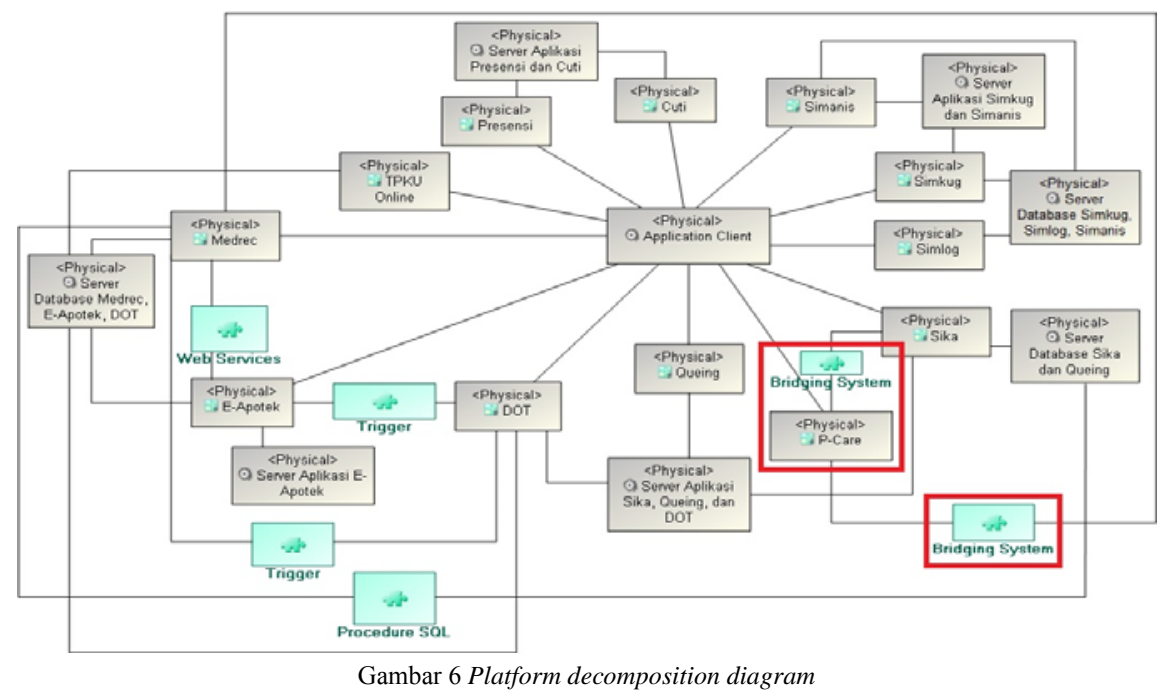

Perancangan dan Analisis Enterprise Architecture Yayasan Kesehatan (Yakes) Telkom pada Domain Arsitektur Teknologi dengan Menggunakan Framework TOGAF ADM Irma Angraeini, Mochamad Teguh Kurniawan, Rahmat Mulyana (hal. 1 - 8) 

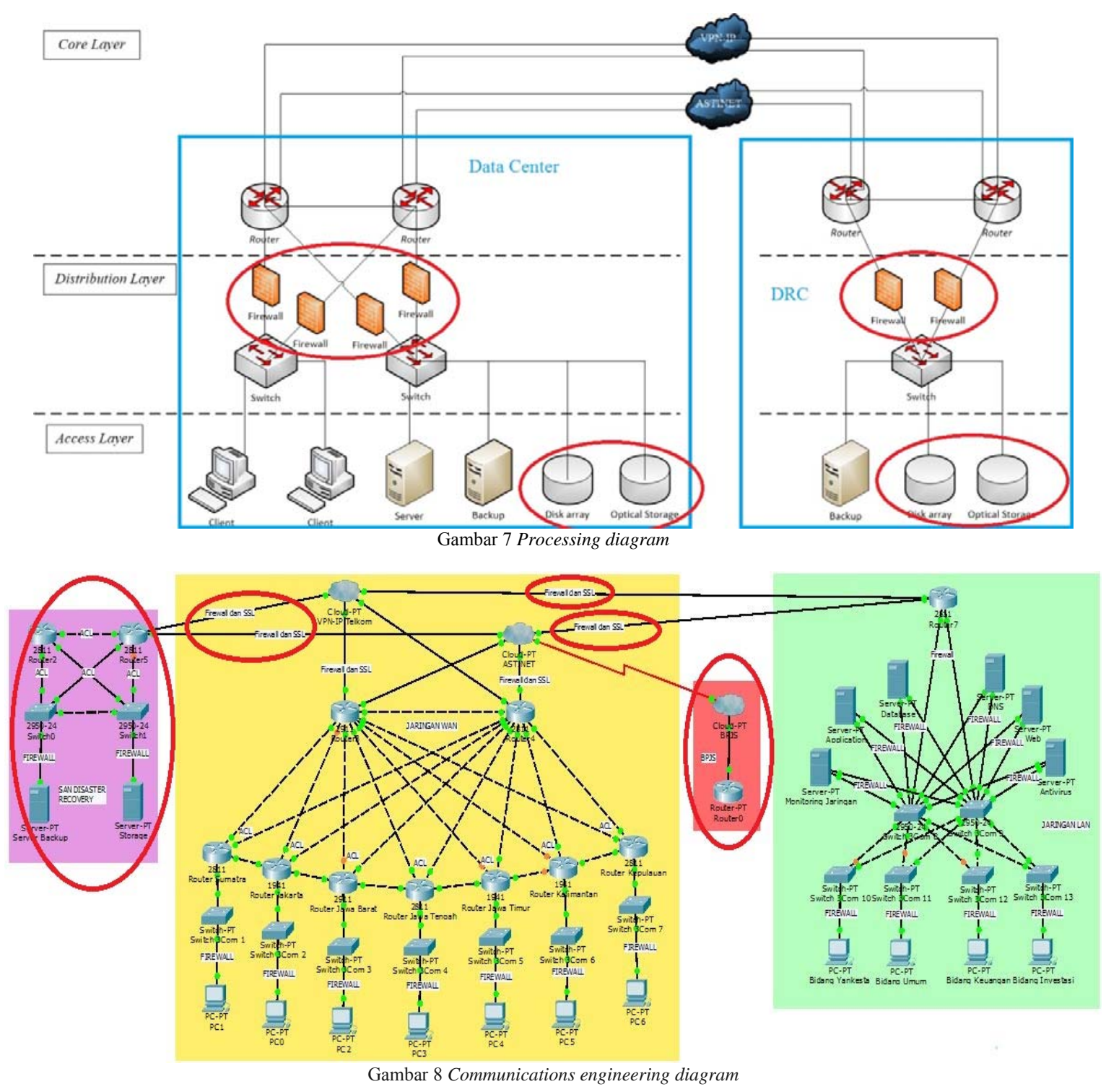

\section{c. Processing diagram}

Processing diagram mengGambarkan interaksi antar unit dan merupakan pengorganisasian serta pengelompokan unit teknologi yang tersebar pada perusahaan (The Open Group, 2011). Pengelompokan ini dilakukan berdasarkan standar hirarki desain infrastruktur jaringan menurut Cisco [8] yaitu three-layer hierarchical design model yang dikelompokkan berdasarkan tiga lapisan yaitu yaitu core layer (lapisan inti), distribution layer (lapisan distribusi), dan access layer (lapisan akses). Gambar 6, terdapat perubahan topologi pada data center dan penambahan disaster recovery center dengan berbasis topologi SAN. Perbedaan dari kondisi teknologi saat ini terletak pada distribution layer yaitu penambahan keamanan jaringan berupa firewall dan pada access layer yaitu terdapat penambahan storage untuk tempat penyimpanan data berupa disk array dan optical storage.

d. Communications engineering diagram

Communications engineering diagram mengGambarkan mengGambarkan sarana komunikasi antar aset di dalam arsitektur teknologi serta mengGambarkan koneksi logis antara client dengan komponen server dan mengidentifikasi batas-batas jaringan dan infrastruktur jaringan yang dibutuhkan untuk mengimplementasikan koneksi fisik tersebut (The Open Group, 2011). Berikut adalah communications engineering diagram dari Yayasan Kesehatan Telkom: 
Gambar 7 menunjukkan adanya penambahan redundansi link dan terdapat penambahan provider Astinet yang dapat menjadi alternatif apabila terjadi permasalahan dalam jaringan. Selain itu, juga terdapat penambahan disaster recovery center sebagai backup apabila terjadi bencana alam serta adanya keterkaitan dengan jaringan WAN milik BPJS.

Dengan adanya diagram di atas menunjukkan adanya peran dari TOGAF ADM yang dapat membantu perusahaan dalam menyelaraskan bisnis dengan IT. Diagram - diagram tersebut mengGambarkan keadaan arsitektur teknologi dari Yayasan Kesehatan Telkom di masa mendatang yang dapat membantu bisnisnya agar dapat berjalan lebih maksimal dengan adanya kerjasama dengan pihak BPJS. TOGAF ADM memungkinkan perusahaan mendefinisikan kebutuhan bisnis yang telah dijelaskan pada penelitian dengan judul "Perancangan dan Analisis Enterprise Architecture Yayasan Kesehatan (Yakes) Telkom pada Domain Arsitektur Bisnis dengan Menggunakan Framework TOGAF ADM" oleh Ratih Cintya Lestari dan membangun arsitektur spesifik seperti yang telah dijelaskan dan diGambarkan pada diagram di atas untuk memenuhi kebutuhan tersebut.

\section{KESIMPULAN}

Berdasarkan hasil perancangan dan analisis yang telah dilakukan dan dijelaskan, maka dapat diambil kesimpulan bahwa arsitektur teknologi dapat membantu Yayasan Kesehatan Telkom untuk melakukan kerjasama dengan BPJS yaitu dengan meningkatkan kondisi infrastruktur jaringan yang ada. Peningkatan tersebut dilakukan dengan cara menambah keamanan jaringan, menambahkan SAN untuk topologi data center dan disaster recovery, serta menambahkan redundansi untuk availability infrastruktur jaringan.

\section{DAFTAR PUSTAKA}

[1] Republik Indonesia, Undang-Undang No. 24 Tahun 2011 tentang Badan Penyelenggara Jaminan Sosial, Jakarta: Sekretariat Negara, 2011.

[2] Pusat Pendidikan dan Pelatihan Manajemen Rumah Sakit Indonesia, "Tantangan Ganda Tahun 2015 Bagi Praktisi Kesehatan Indonesia," no. BPJS, 2015.

[3] A. G. Herucakra, A. Fajar and R. Hanafi, "Analisis dan Perancangan Enterprise Architecture untuk Mendukung Fungsi Terkait System Online Payment PointMenggunakan Framework TOGAF ADM pada PT Pos Indonesia," p. 2, 2012.

[4] R. Yunis and K. Surendro, "Perancangan Mmodel Enterprise Architecture dengan TOGAF Architecture Development Method," Seminar Nasional Aplikasi Teknologi Informasi, pp. E-28, 2009.

[5] The Open Group, Sample Catalogs, Matrices, and Diagrams, The Open Group, 2011.

[6] The Open Group, TOGAF version 9, The Open Group, 2009.

[7] The Open Group, Sample Catalogs, Matrices and Diagrams, The Open Group, 2011.

[8] Cisco, "The Hierarchical Network Design Model," 2003. [Online]. Available: http://www.cisco.com/web/learning/netacad/demos/C CNP1v30/ch1/1_1_1/index.html. [Accessed 24 May 2015]. 